\title{
Comparison of properties inherent to thin titanium oxide films formed by rapid thermal annealing on $\mathrm{SiC}$ and porous $\mathrm{SiC}$ substrates
}

\author{
Yu.Yu. Bacherikov ${ }^{1}$,N.L. Dmitruk ${ }^{1}$, R.V. Konakova ${ }^{1}$, O.F. Kolomys ${ }^{1}$, O.B. Okhrimenko ${ }^{1, *}$, V.V. Strelchuk ${ }^{1}$, \\ O.S. Lytvyn ${ }^{2}$, L.M. Kapitanchuk ${ }^{3}$, A.M. Svetlichnyi ${ }^{4}$ \\ ${ }^{I}$ V. Lashkaryov Institute of Semiconductor Physics, NAS of Ukraine, Kyiv, Ukraine \\ *E-mail: olga@isp.kiev.ua \\ ${ }^{2}$ Borys Grinchenko Kyiv University, Kyiv, Ukraine \\ ${ }^{3}$ Paton Institute of Electric Welding, NAS of Ukraine, Kyiv, Ukraine \\ ${ }^{4}$ Institute of Nanotechnologies, Electronics, and Electronic Equipment Engineering, \\ Southern Federal University, Taganrog, Russia
}

\begin{abstract}
The comparative analysis of optical characteristics inherent to $\mathrm{TiO}_{2} / \mathrm{SiC}$ and $\mathrm{TiO}_{2} /$ por-SiC/SiC structures has been performed. It has been shown that, in these structures regardless of the substrate structure, formation of $\mathrm{TiO}_{2}$ layers with approximately the same width $60 \mathrm{~nm}$ takes place. In this case the $\mathrm{TiO}_{2}$ film composition is close to the stoichiometric one. At the same time, the presence of an additional porous layer in the $\mathrm{TiO}_{2} /$ por-SiC/SiC structure leads to blurring the oxide film - substrate interface but promotes an increase in the intensity of the Raman scattering signal from the oxide film.
\end{abstract}

Keywords: thin titanium oxide films, $\mathrm{SiC}$ substrates, interface, porous layer.

doi: https://doi.org/10.15407/spqeo21.02.200

PACS 77.55.-g, 78.55.Qr, 81.15.-z

Manuscript received 07.06.18; revised version received 05.06.18; accepted for publication 27.06.18; published online 03.07.18.

\section{Introduction}

The continuing interest in silicon carbide as a material for fabrication of semiconductor devices operating under extreme conditions is explained by a combination of such factors as a wide forbidden band, high electron mobility, chemical and mechanical resistance [1-3]. All this determines the possibility to use it in devices capable to operate at elevated temperatures, elevated irradiation doses, with high speed and high stability of their properties in time.

At present, the urgent task for high-temperature electronics based on silicon carbide is to develop stable high-quality dielectric layers, including those based on titanium oxide films. Despite the wide range of technological possibilities for creation of oxide metal films (from anodic to oxidation in air or in the atmosphere of oxygen, water and water vapor, in carbon dioxide or in various other gas mixtures [4]), the search for well-controlled, fast methods of formation with high reproducibility of parameters of oxide metal films with set properties are being performed up to date.
It is known that the structural defects of a semiconductor substrate, which penetrate into a thin film grown on this substrate during a high-temperature process, can significantly worsen the characteristics of devices. One way for reducing this effect is to create a porous interlayer between the substrate and epitaxial layer [5, 6]. For example, the layers of porous silicon carbide (por-SiC) are used in complex structures to decrease the concentration of defects at the boundary 'porous layer - epitaxial film' [6-10].

In addition, the pore-developed surface makes porous silicon carbide a promising material for sensitive elements of sensors with both the Schottky barriers and MIS structures [11]. The principle of operation of many devices is based on changes in the potential barrier of contact typical for porous $\mathrm{SiC}$ with metal or dielectric. In these cases, an important role is played by processes occurring at the boundary of the porous silicon carbide with metallic or dielectric layers.

In this paper, we have performed the comparative studies of $\mathrm{TiO}_{2}$ films formed by rapid thermal annealing on silicon carbide substrates in the presence and absence of a porous $\mathrm{SiC}$ layer. 


\section{Samples and experimental procedure}

The oxide films $\mathrm{TiO}_{2}$ were prepared by oxidizing thin $\mathrm{Ti}$ metal films by using rapid thermal annealing at $T=$ $323{ }^{\circ} \mathrm{C}$ for 1,3 and $5 \mathrm{~s}$.

To form the $\mathrm{SiC} /$ por-SiC/TiO 2 structure on a silicon carbide substrate, a por-SiC layer was preliminarily prepared. Porous silicon carbide was created using anodic etching of silicon carbide in a hydro-alcohol solution of hydrofluoric acid: $\mathrm{H}_{2} \mathrm{O}: \mathrm{HF}: \mathrm{C}_{2} \mathrm{H}_{5} \mathrm{OH}=1: 1: 2$, the current density was $20 \mathrm{~mA} / \mathrm{cm}^{2}$, and the etching time was $5 \mathrm{~min}$. Then, the material was processed in the etchant $\mathrm{KNO}_{3}+\mathrm{KOH}$ to open the pores. Formation of the oxide film $\mathrm{TiO}_{2}$ was carried out in several technological stages. On the surface of porous silicon carbide, a titanium film was deposited using a thermal deposition method. Then, the samples of porous $\mathrm{SiC}$ with introduced $\mathrm{Ti}$ were annealed in vacuum at $1350{ }^{\circ} \mathrm{C}$ for $8 \mathrm{~min}$, after which they were subjected to rapid thermal annealing in atmosphere of dry oxygen for $30 \mathrm{~s}$ at the temperatures 700,900 and $1000^{\circ} \mathrm{C}[12,13]$.

The thickness of the oxide layers was determined using the method of multibeam monochromatic ellipsometry. On all the samples, morphology of the coating was studied using the atomic force microscope NanoScopeIIIa (DJ). The atomic composition of the structures under investigation was measured using the Auger spectrometer LAS-2000, when layer-by-layer etching the samples with 1-keV Ar ions was used.

The micro-Raman spectra of the samples were measured at room temperature in the backscattering geometry by using the Horba Jobin Yvon T64000 spectrometer with a confocal microscope (100× lens, 0.90 diaphragm) and cooled CCD detector. The Raman spectra were excited by an Ar-Kr laser $\lambda_{\text {exc }}=488.0 \mathrm{~nm}$ ). In Raman studies, the laser beam was focused into a beam of diameter $<1 \mu \mathrm{m}$. The accuracy of determining the frequency position of the phonon lines was $0.15 \mathrm{~cm}^{-1}$.

\section{Experimental results and discussion}

Calculation of the thickness of the oxide metal film was carried out using the method of multi-beam monochromatic ellipsometry (operating wavelength $\lambda=$ $632.8 \mathrm{~nm})$.

Parameters of the films were determined from the model of a single-layer film on a substrate as a result of fitting the calculated angular dependences of the polarization angles $\psi$ and $\Delta$ to the experimental dependences $\psi(\varphi)$ and $\Delta(\varphi)$ by using the computer program for minimizing the special objective function $S(x)[14]$

$$
\begin{aligned}
& S(x)=\frac{1}{N} \sum_{i=1}^{N}\left[\frac{\left(\psi\left(x, \varphi_{i}\right)-\psi^{\prime}\left(\varphi_{i}\right)\right)^{2}}{\left(\delta \psi^{\prime}\left(\varphi_{i}\right)\right)^{2}}+\frac{\left(\Delta\left(x, \varphi_{i}\right)-\Delta^{\prime}\left(\varphi_{i}\right)\right)^{2}}{\left(\delta \Delta^{\prime}\left(\varphi_{i}\right)\right)^{2}}\right] \times \\
& \times \sum_{i=1}^{N}\left[\left(\delta \psi^{\prime}\left(\varphi_{i}\right)\right)^{2}+\left(\delta \Delta^{\prime}\left(\varphi_{i}\right)\right)^{2}\right],
\end{aligned}
$$

where $\psi^{\prime}\left(\varphi_{i}\right)$ and $\Delta^{\prime}\left(\varphi_{i}\right)$ are the experimentally measured polarization angles at an angle of incidence $\varphi_{i} ; \psi^{\prime}\left(x, \varphi_{i}\right)$ and $\Delta^{\prime}\left(x, \varphi_{i}\right)$ are the results of calculation of the direct problem of ellipsometry for the angle $\varphi_{i}$ and vector of optical parameters and layer thicknesses $x ; \delta \psi^{\prime}\left(\varphi_{i}\right)$ and $\delta \Delta^{\prime}\left(\varphi_{i}\right)$ - measurement errors, $N$ - total number of the used angles of incidence.

As control data, the values of absorption and refractive indexes for silicon carbide were calculated. The refractive index $n_{\mathrm{SiC}}$ calculated on the basis of the ellipsometric measurement data is in good agreement with the expected averaged value (without account of anisotropy), and the absorption index $k_{\mathrm{SiC}}$ for $\lambda=$ $632.8 \mathrm{~nm}$ is very small, which is a confirmation of the accuracy inherent to the method.

A comparison of the thicknesses of the oxide layers determined using the method of multi-beam ellipsometry has shown that, both in the case of the presence of a buffer layer and in its absence, layers of approximately the same width $60 \mathrm{~nm}$ were formed, which correlates with the Auger spectrometry data.

Figs 1 (upper and lower) show AFM images of oxide titanium films on single-crystal and porous substrates, respectively. As can be seen from Fig. 1, the oxide film has an inhomogeneous character and granular structure.
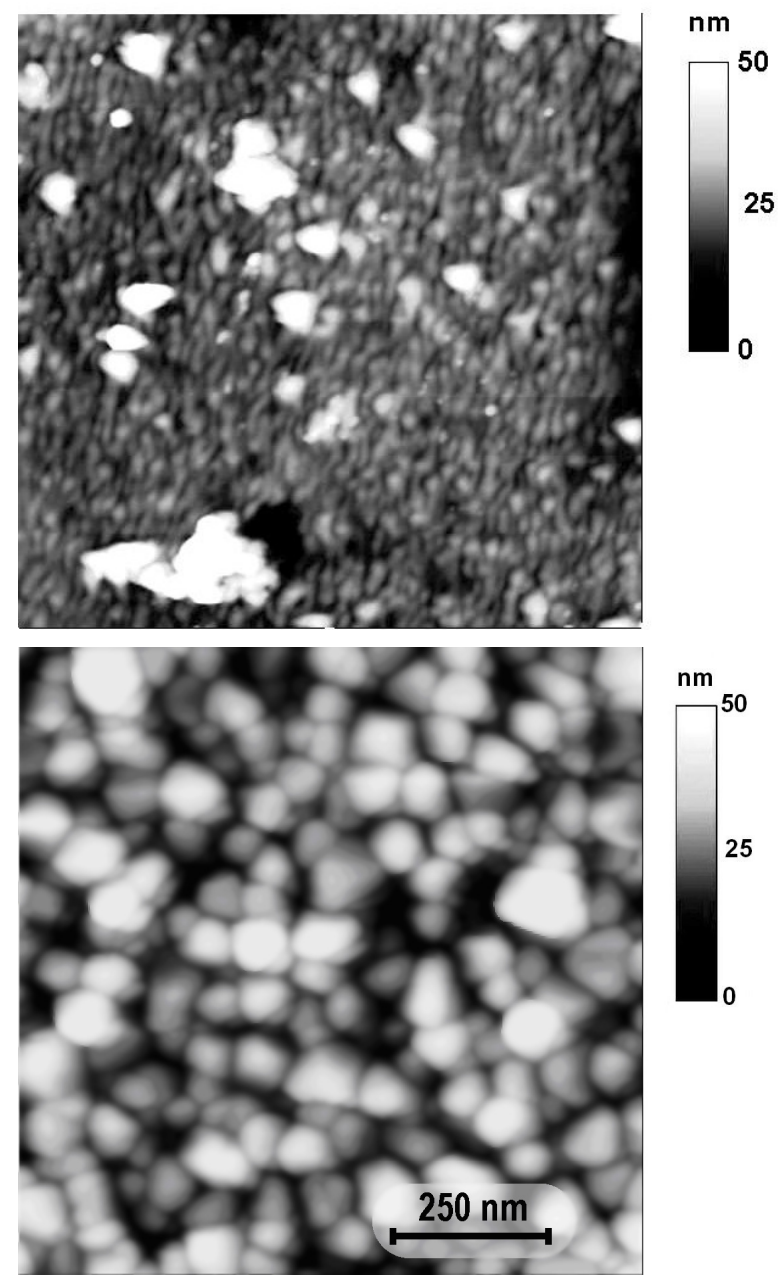

Fig. 1. AFM images of the surface of the $\mathrm{SiC} / \mathrm{TiO}_{2}$ (upper) and $\mathrm{SiC} /$ por-SiC/TiO 2 (lower) structures.

Bacherikov Yu.Yu., Dmitruk N.L., Konakova R.V., et al. Comparison of properties inherent to thin titanium oxide ... 

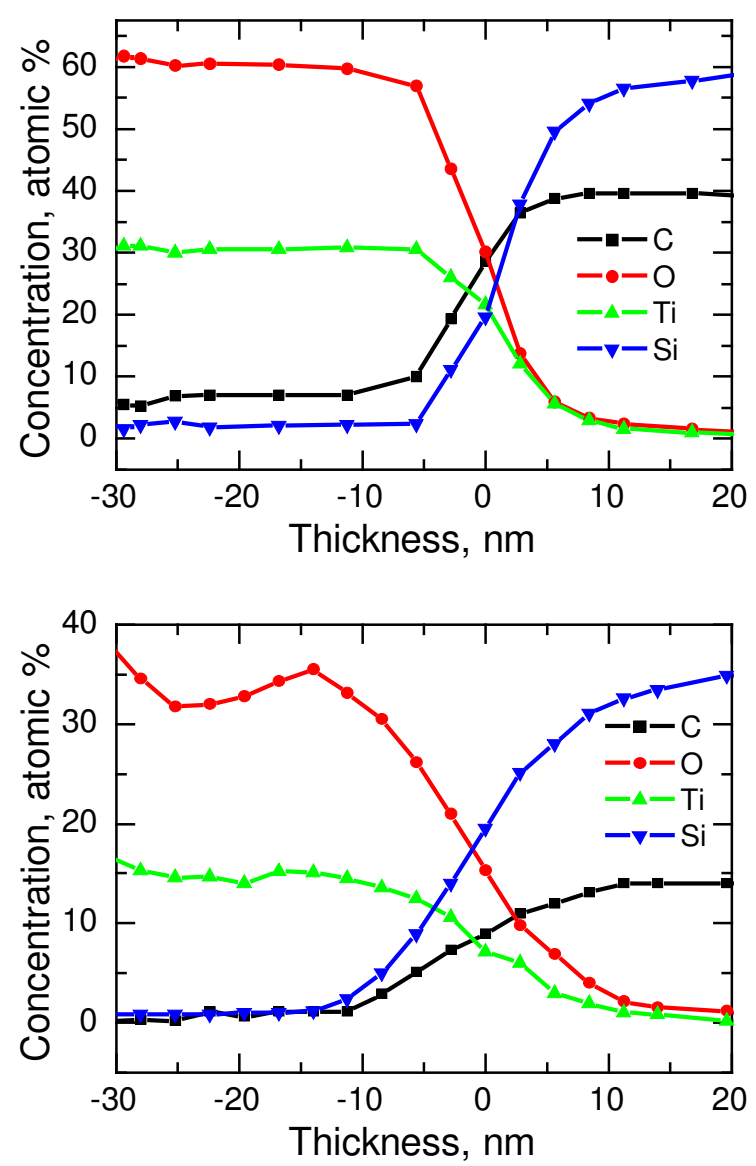

Fig. 2. The contents of elements in atomic percentages in the $\mathrm{SiC} / \mathrm{TiO}_{2}$ (upper) and $\mathrm{SiC} /$ por-SiC/TiO 2 (lower) structures.

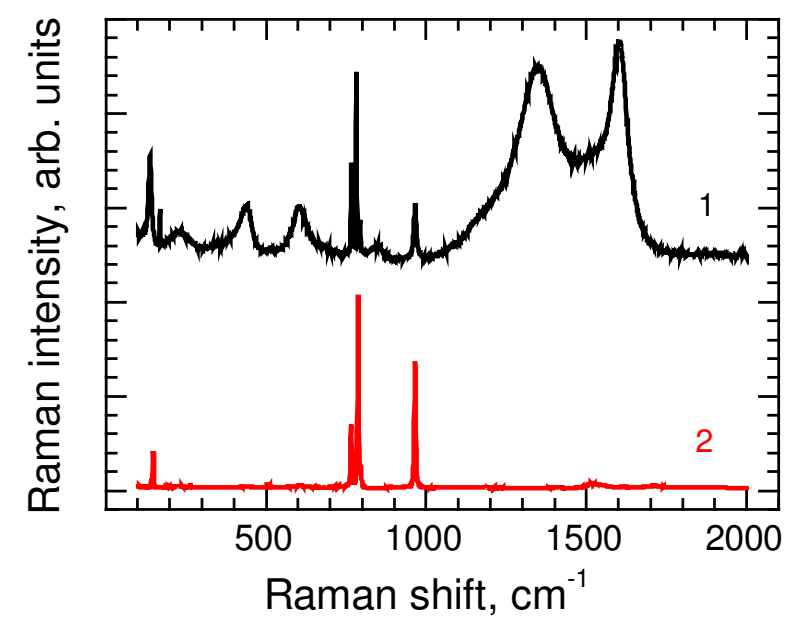

Fig. 3. Raman spectra for the $\mathrm{SiC} / \mathrm{TiO}_{2}$ (1) and $\mathrm{SiC} /$ por$\mathrm{SiC} / \mathrm{TiO}_{2}(2)$ structures.

Fig. 2 shows the atomic profiles of heterostructures formed by titanium oxide on the $\mathrm{SiC}$ substrate in the absence and presence of a por-SiC buffer layer at the oxide-semiconductor interface.

According to $[15,16]$, the phase equilibrium in the titanium-oxygen system is characterized by the presence of several phases: $\mathrm{TiO}, \mathrm{Ti}_{2} \mathrm{O}_{3}, \mathrm{TiO}_{2}$. Moreover, the $\mathrm{TiO}_{2}$ phase can be available in one of three modifications: anatase, brookite and rutile $[17,18]$. The lowtemperature modification - anatase - turns into rutile when heated. Typically, this transition to the rutile modification takes place within the temperature range from 650 to $900{ }^{\circ} \mathrm{C}$. The second modification of titanium dioxide - brookite - turns also into rutile when heated to $\sim 1000^{\circ} \mathrm{C}$. In this case, the defect structure of the rutile itself depends essentially on the processing temperature $[15,16]$.

As can be seen from Fig. 2, the ratio of the Ti oxide components for the oxides, which form directly on the $\mathrm{SiC}$ crystal substrate and in the presence of the por-SiC buffer layer, is close to the stoichiometric composition of titanium dioxide: $N_{\mathrm{O}} / N_{\mathrm{Ti}} \approx 1.98$ and $N_{\mathrm{O}} / N_{\mathrm{Ti}} \approx 2.2$, respectively.

As it follows from the analysis of the distribution of atomic components (Fig. 2), the stoichiometric composition of these oxide titanium layers corresponds to the modification of titanium dioxide with the rutile structure. At the same time, the chemical composition of oxide film - substrate interface differs from the bulk of oxides (Fig. 2).

As in the case of $\mathrm{SiC} / \mathrm{Er}_{2} \mathrm{O}_{3}$ and $\mathrm{SiC} /$ por-SiC/ $/ \mathrm{Er}_{2} \mathrm{O}_{3}$ structures [19], a sharper interface 'oxide film substrate' is observed when the $\mathrm{TiO}_{2}$ is directly formed on the crystalline substrate.

Fig. 3 shows the Raman spectra for $\mathrm{SiC} / \mathrm{TiO}_{2}$ and $\mathrm{SiC} /$ por-SiC/TiO 2 structures.

As can be seen from Fig. 3, in the Raman spectra of the $\mathrm{SiC} /$ por-SiC/TiO ${ }_{2}$ structure in the $300 \ldots 600 \mathrm{~cm}^{-1}$ region (Fig. 3, curve 2), in addition to the lines with the frequencies $262.7,502.37$ and $511.07 \mathrm{~cm}^{-1}$ typical for por-SiC, we observe the lines with the frequencies of 435 and $603 \mathrm{~cm}^{-1}$ that indicate formation of a titanium oxide film on the por-SiC surface [20, 21], which correlates with the Auger spectrometry data (Fig. 2b). At the same time, in the Raman scattering spectra of the $\mathrm{SiC} / \mathrm{TiO}_{2}$ structure, the lines characteristic for the Raman spectrum of $\mathrm{TiO}_{2}$ are not observed (Fig. 3, curve 2), although the Auger spectrometry data indicate the presence of titanium oxide in the thin film structure (Fig. 2a). It is caused by the fact that the intensity of the Raman spectra is proportional to the thickness of the layer, and for a very small thickness of the oxide film the intensity of the Raman signal from the $\mathrm{TiO}_{2}$ film is very small as compared to that of the signal from the substrate. At the same time, a surface-enhanced Raman scattering signal (SERS) is likely to occur due to the presence of a porous layer, as well as due to the presence of under-oxidized metal particles in it, as evidenced by the blurring of the interface in the $\mathrm{SiC} /$ por-SiC/TiO 2 structure (Fig. 2b).

In addition to the Raman bands caused by the titanium oxide film on the por-SiC surface, in the Raman spectra of the $\mathrm{SiC} /$ por-SiC/TiO 2 structure, we observe the lines with the frequencies of 1345 and $1601 \mathrm{~cm}^{-1}$ (Fig. 3, curve 2), which are characteristic for the compounds of carbon [22, 23]. These lines are typical for the graphite phase in por-SiC, the appearance of which is associated with high-temperature annealing of por-SiC [24]. When being thermally treated in vacuum, the surface of $\mathrm{SiC}$ 
tends to be graphitized during thermal decomposition of $\mathrm{SiC}$ and evaporation of $\mathrm{Si}$ atoms [24]. It was shown in [24] that graphitization of the por-SiC layer can begin at the temperatures close to $700{ }^{\circ} \mathrm{C}$, and the quasiamorphous carbon phase of the graphitized type can appear on the pore surface.

\section{Conclusions}

Thus, regardless of the substrate structure, during the rapid thermal annealing, we have obtained the $\mathrm{TiO}_{2}$ layers of approximately the same width $60 \mathrm{~nm}$ with the composition close to the stoichiometric one. In this case, in the $\mathrm{SiC} /$ por- $\mathrm{SiC} / \mathrm{TiO}_{2}$ structures, the graphite phase is formed in the por-SiC/TiO ${ }_{2}$ interface, which degrades the quality of the interface. At the same time, the presence of a porous layer makes it possible to enhance the Raman signal from a thin $\mathrm{TiO}_{2}$ film, which opens the perspective of using the por-SiC buffer layer as a substrate for SERS.

\section{References}

1. Lebedev A.A., Chelnokov V.E. Wide-gap semiconductors for high-power electronics. Semiconductors. 1999. 33. P. 999-1001.

2. Schürmann M., Dreiner S., Berges U., Westphal C., Choi S.H., Wang D., Williams J.R., Park M., Lu W., Dhar S., Feldman L.C. J. Ultrathin $\mathrm{SiO}_{2}$-films on $4 \mathrm{H}-\mathrm{SiC}(0001)$ studied by angle-scanned photoelectron diffraction. Electron Spectroscopy and Related Phenomena. 2007. 156-158. P. 119.

3. Virojanadara C., Johansson L.I. Photoemission study of Si-rich $4 \mathrm{H}-\mathrm{SiC}$ surfaces and initial $\mathrm{SiO}_{2} / \mathrm{SiC}$ interface formation. Phys. Rev. B. 2005. 71. P. 195335.

4. L'oxydation des métaux, Tome I, Processus fondamentaux [Texte imprimé]. Sous la direction de Jacques Bénard,...; avec la collaboration de Jean Bardolle, Florent Bouillon, Michel Cagnet... [et al.]. Paris: Gauthier-Villars et cie, DL 1962 [Okisleniye metallov, red. Benar Zh. T. 1: Teoreticheskiye osnovy, per.: Masterovaya M.G., Tsypin M.I.; red. Viktorovich G.S. Moscow: Metallurgiya, 1968 (in Russian)].

5. Mynbaeva M.G., Lavrent'ev A.A., Kuznetsov N.I., Kuznetsov A.N., Mynbaev K.D., Lebedev A.A. Semi-insulating silicon carbide layers obtained by diffusion of vanadium into porous $4 \mathrm{H}-\mathrm{SiC}$. Semiconductors. 2003. 37. P. 594-597.

6. Savkina N.S., Ratnikov V.V., Rogachev A.Yu., Shuman V.B., Tregubova A.S., Volkova A.A. Structure and properties of silicon carbide grown on porous substrate by vacuum sublimation epitaxy. Semiconductors. 2002. 36. P. 758-762.

7. Sorokin L.M., Savkina N.S., Shuman V.B., Lebedev A.A., Mosina G.N., Hutchison G. Features of the structure of a porous silicon carbide layer obtained by electrochemical etching of a $6 \mathrm{H}-\mathrm{SiC}$ substrate. Tech. Phys. Lett. 2002. 28. P. 935-938.
8. Polupan G., Torchynska T.V. Surface phonons and exciton-polariton coupling in $\mathrm{SiC}$ nanocrystals. Thin Solid Films. 2010. 518. P. S208-S211.

9. Torchynska T.V., Díaz Cano A., Dybic M., Ostapenko S., Mynbaeva M. Stimulation of excitonic and defect-related luminescence in porous SiC. Physica B. 2006. 376-377. P. 367-369.

10. Sagar Ashutosh, Feenstra R.M., Inoki C.K., Kuan T.S., Koleske D.D. Combined MOCVD and MBE growth of GaN on porous SiC. Mat. Res. Soc. Symp. Proc. 2004. 798. Y9.6.

11. Nguyen P., Pham Ch. Innovative porous SiC-based materials: From nanoscopic understandings to tunable carriers serving catalytic needs. Applied Catalysis A: General. 2011. 391. P. 443-454.

12. Bacherikov Yu.Yu., Konakova R.V., Lytvyn O.S., Okhrimenko O.B., Svetlichnyi A.M., Moskovchenko N.N. Morphology and optical properties of titanium-doped porous silicon carbide layers. Tech. Phys. Lett. 2006. 32. P. 140-142.

13. Bacherikov Yu.Yu., Dmitruk N.L., Konakova R.V., Kondratenko O.S., Milenin V.V., Okhrimenko O.B., Kapitanchuk L.M., Svetlichnyi A.M., Moskovchenko N.N. Formation of titanium oxide films on the surface of porous silicon carbide. Tech. Phys. 2008. 53. P. 1232-1235.

14. Antonyuk V.N. Dmitruk N.L., Medvedeva M.F. Determination of the optical constants of the real and anodic oxidized GaAs surfaces by using the method of multiple-angle-of-incidence ellipsometry, in: Ellipsometry in Science and Technology. Mardezhov A.S. (ed.). Novosibirsk, 1987, p. 66-71 (in Russian).

15. Valeeva A.A., Rempel' A.A., Gusev A.I. Twosublattice ordering in titanium monoxide. JETP Lett. 2000. 71. P. 460-464.

16. Ageev V.N., Afanas'eva E.Yu., Potekhina N.D. Oxidation kinetics of thin titanium films grown on tungsten. Phys. Solid State. 2004. 46. P. 1542-1547.

17. Mitrev P., Benvenuti G., Hofman P., Smirnov A., Kaliteevskaya N., Seisyan R. Phase transitions in thin titanium oxide films under the action of excimer laser radiation. Tech. Phys. Lett. 2005. 31. P. 908-911.

18. Goncharov A.A., Demchishin A.V., Demchishin A.A., Kostin E.G., Michenko V.A., Stetsenko B.V., Ternovoi E.G., Shchurenko A.I. Characteristics of a cylindrical magnetron and reactive sputtering of binary compound films. Tech. Phys. 2007. 52. P. 1073-1078.

19. Bacherikov Yu.Yu., Konakova R.V., Okhrimenko O.B., Berezovska N.I., Kapitanchuk L.M., Svetlichnyi A.M. Optical properties of thin erbium oxide films formed by rapid thermal annealing on $\mathrm{SiC}$ substrates with different structures. SPQEO. 2017. 20. P. 465-469.

20. Handbook of Minerals Raman Spectra. Laboratoire de géologie de Lyon ENS-Lyon France: http://www.ens-lyon.fr/LST/Raman/. 
21. Romanian Database of Raman Spectroscopy: http://rdrs.uaic.ro/index.html

22. Lebedev A.A., Kotousova I.S., Lavrent'ev A.V., Lebedev S.P., Dement'ev P.A., Petrov V.N., Smirnov A.N., Titkov A.N., Study of multigraphene films prepared by sublimation on the SiC surface. Phys. Solid State. 2010. 52. P. 855-861.

23. Lebedev A.A., Agrinskaya N.V., Lebedev S.P., Mynbaeva M.G., Petrov V.N., Smirnov A.N., Strel'chuk A.M., Titkov A.N., Shamshur D.V. Lowtemperature transport properties of multigraphene films grown on the SiC surface by sublimation. Semiconductors. 2011. 45. P. 623-627.

24. Shuman V.B., Savkina N.S. Graphitization of porous $6 \mathrm{H}-\mathrm{SiC}$ layers during thermal treatment in vacuum. Tech. Phys. Lett. 2004. 30, No 7. P. 572574.

\section{Authors and CV}

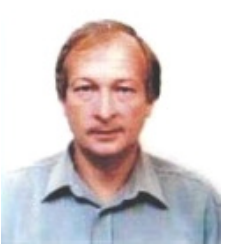

Yuriy Yu. Bacherikov, born in 1960, defended his Doctoral Dissertation in Physics and Mathematics in 2010. Leading scientific collaborator at V. Lashkaryov Institute of Semiconductor Physics, NAS of

Ukraine. Authored over 300 publications, 6 patents, one monograph. The area of his scientific interests includes physics and applications of wide-band semiconductor compounds and devices based on them

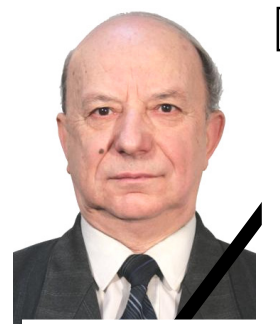

Mykola L. Dmytruk (1938 - 2017), defended his Doctoral Dissertation in Physics and Mathematics in 2004 and became full professor in 2008. Head of department at V. Lashkaryov Institute of Semiconductor Physics, NAS of Ukraine. Authored over 400 publications, 5 patents, 4 textbooks.

The area of his scientific interests included the combination of electrophysical methods for studying electronic phenomena on the surface of semiconductors and optics of solid surfaces (polariton phenomena, nanoplasmonics).

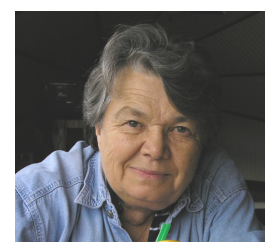

Raisa V. Konakova born in 1941, defended his Doctoral Dissertation in Technical Physics in 1987 and became full professor in 1991. Professor at Laboratory of Physical and Technological Problems of SolidState Microwave Electronics, V. Lashkaryov Institute of Semiconductor Physics, NAS of Ukraine. Authored over 600 publications, 85 patents, 14 textbooks. The area of her scientific interests includes physics, technology and diagnostics of microwave semiconductor devices.

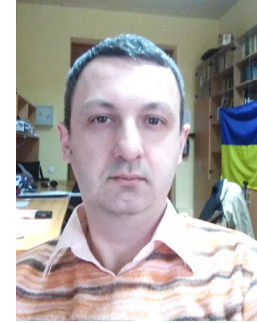

Oleksandr F. Kolomys, born in 1979, defended his PhD dissertation in Physics and Mathematics in 2006. Senior Researcher at Laboratory of submicron optical spectroscopy, V. Lashkaryov Institute of Semiconductor Physics, NAS of Ukraine. Authored over 130 publications, 3 patents, 3 chapters in textbooks. The area of his scientific interests includes Raman and luminescent microanalysis of light emitting properties, structure, composition, electronic and phonon excitations in solids, physical and chemical properties of semiconductors, chemicals and nanostructures for modern micro-, nanoand optoelectronics with submicron spatial resolution.

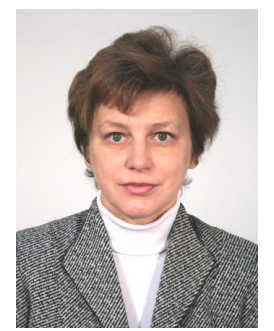

Olga B. Okhrimenko, born in 1963, defended his Doctoral Dissertation in Physics and Mathematics in 2016. Leading scientific collaborator at V. Lashkaryov Institute of Semiconductor Physics, NAS of Ukraine. Authored over 135 publications, one patent and one monograph. The area of her scientific interests includes investigation of the patterns and physical mechanisms providing formation and rearrangement of defectimpurity systems inherent to thin-film dielectricsemiconductor structures, depending on technology of preparation, composition of thin films, additional processing and introduction of buffer layers.

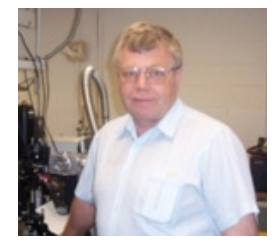

Viktor V. Strelchuk, born in 1957, defended his Doctoral Dissertation in Physics and Mathematics in 2006 and became full professor in 2016. Professor at Laboratory of submicron optical spectroscopy, V. Lashkaryov Institute of Semiconductor Physics, NAS of Ukraine. Authored over 300 publications, 10 patents, 6 textbooks. The area of his scientific interests includes optical spectroscopy of low-dimension structures, technology, physics and applications of semiconductors and their nanostructures, confocal Raman spectroscopy, FTIR.

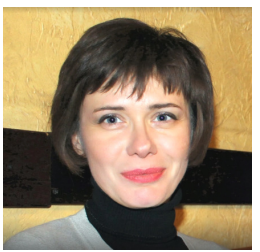

Oksana S. Lytvyn, born in 1970, defended her Candidate Dissertation in Physics and Mathematics in 2001 and became senior researcher in 2007. Head of Information technologies and mathematic disciplines Chair at the Borys Grinchenko Kyiv University. Authored over 200 publications, 2 patents. The area of her scientific interests includes scanning probe microscopy diagnostics of physical and mechanical surface properties of various materials (thin films and low-dimensional systems, composites). 


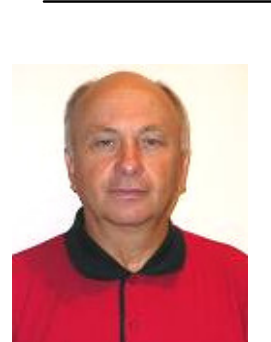

Leonid M. Kapitanchuk, born in 1948. Researcher at E. O. Paton Electric Welding Institute, National Academy of Sciences of Ukraine. Authored over 82 publications and 2 patents. The area of his scientific interests includes materials science, Auger electron spectroscopy, X-ray spectroscopy.

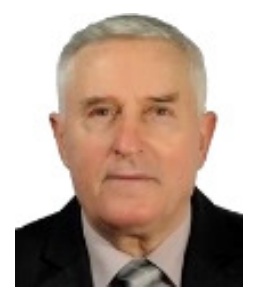

Aleksandr M. Svetlichnyi born in 1941, defended his Candidate Dissertation in Technical in 1974. Associate Professor at the Institute of Nanotechnologies, Electronics and Equipment Engineering. Authored over 300 publications, 30 patents, 6 textbooks. The area of his scientific interests includes defects in the crystal structure of semiconductors and their influence on the instrument parameters, quality control of manufacturing processes of integrated circuits on the noise characteristics, the development of equipment and manufacturing processes of integrated circuits on the basis of coherent (laser) and non-coherent radiation sources. 